\title{
Cortisol level and suicidal risk
}

Beuy Joob ${ }^{1 *}$ and Viroj Wiwanitkit ${ }^{2}$

Dear Editor,

The publication on "cortisol level and suicidal risk" by Ahmed et al. is very interesting (Ahmed et al. 2016). Ahmed et al. concluded that "There are relatively increased levels of morning and evening cortisol in major depressive disorder patients in comparison with controls; thoughts of death are positively associated with elevated morning and evening cortisol level (Ahmed et al. 2016)". In fact, there are many factors that might results in aberration of cortisol level. In the present study, the control of confounding factor is questionable. The control of venipuncture pain and hemolysis which is an important primary inference on blood cortisol level should be considered (Lima-Oliveira et al. 2013; Snyder et al. 2004) and there is a remained question on the present study by Ahmed et al. (Ahmed et al. 2016) on the mentioned confounding factor. In clinical chemistry laboratory diagnostic test, the aberration of cortisol level can be seen in case with venipuncture pain and hemolytic samples (Lima-Oliveira et al. 2013; Snyder et al. 2004).

\section{Acknowledgements}

Not applicable.

Funding

None.

Availability of data and materials

Data sharing not applicable to this article as no datasets were generated or analysed during the current study.

\section{Authors' contributions}

JB participated in its design and coordination, helped to draft the manuscript, and read and approved the final manuscript. W participated in its design and coordination, helped to draft the manuscript, and read and approved the final manuscript.

Ethics approval and consent to participate Not applicable.

\section{Consent for publication}

Not applicable.

\section{Competing interests}

The authors declare that they have no competing interests.

\section{Publisher's Note}

Springer Nature remains neutral with regard to jurisdictional claims in published maps and institutional affiliations.

\section{Author details}

${ }^{1}$ Sanitaton 1 Medical Academic Center, Bangkok 10330, Thailand. ${ }^{2}$ Hainan Medical University, Haikou, China.

Received: 5 January 2018 Accepted: 8 August 2018

Published online: 24 August 2018

\section{References}

Ahmed S, Moussa F, Moustafa A, Ayoub DR. Cortisol level in depressed patients and its relation with suicidal risk and anhedonia. Egypt J Neurol Psychiatry Neurosurg. 2016;53:193-9.

Lima-Oliveira G, Lippi G, Salvagno GL, Montagnana M, Picheth G, Guidi GC. Quality impact on diagnostic blood specimen collection using a new device to relieve venipuncture pain. Indian J Clin Biochem. 2013;28(3):235-41.

Snyder JA, Rogers MW, King MS, Phillips JC, Chapman JF, Hammett-Stabler CA. The impact of hemolysis on ortho-clinical diagnostic's ECi and Roche's elecsys immunoassay systems. Clin Chim Acta. 2004;348(1-2):181-7.

* Correspondence: beuyjoob@hotmal.com

'Sanitaton 1 Medical Academic Center, Bangkok 10330, Thailand

Full list of author information is available at the end of the article 